\title{
PERCEPTIONS AND EXPECTATIONS OF DOCTORS AND NURSES TOWARDS CLINICAL PHARMACY SERVICES IN TAWAU HOSPITAL
}

\author{
MELISSA LIM VEN CHING ${ }^{1,2^{*}}$, LING HUI CHIN² AND NG WAI YIN² \\ ${ }^{1}$ Biro Pengawalan Farmaseutikal Kebangsaan, Kementerian Kesihatan Malaysia, \\ Selangor, Malaysia \\ ${ }^{2}$ Department of Pharmacy, Hospital Tawau, Sabah, Malaysia
}

Published online: 31 May 2020

To cite this article: MELISSA LIM VEN CHING, LING HUI CHIN \& NG WAI YIN (2020) Perceptions and expectations of doctors and nurses towards clinical pharmacy services in Tawau Hospital, Malaysian Journal of Pharmaceutical Sciences, 18(1): 1-14, https://doi.org/10.21315/mjps2020.18.1.1.

To link to this article: $\mathrm{https://doi.org/10.21315/mjps2020.18.1.1}$

Comfort and acceptance by healthcare professionals are crucial for effective operation of clinical pharmacy services. To date, there is no published report on the perceptions towards clinical pharmacy services from Tawau, Sabah or anywhere else in Malaysia. The objective of this study is to evaluate the comfort, perceptions and expectations of healthcare professionals towards the clinical pharmacy services in Tawau Hospital. This crosssectional, questionnaire-based study was carried out in 10 wards of Tawau Hospital with clinical pharmacy services, from June to July 2014. Validated questionnaires with consent were anonymously distributed to doctors and nurses. The self-administered questionnaires consisted of four sections: demographic, comfort level, expectations, and experiences dealing with clinical pharmacists. A 4-point Likert scale, where $1=$ strongly disagree, while 4 = strongly agree, was used to indicate the level of agreement. Of 292 questionnaires administered, 269 were completed, giving a response rate of $92.1 \%$. Compared to nurses, higher percentage of doctors were less comfortable with clinical pharmacists providing drugrelated education, suggesting the use of drugs to prescribers, designing pharmacotherapy regimes, and monitoring safety and outcomes of the designed regimens. The participants have great expectations, perceptions and experiences with clinical pharmacists of Tawau Hospital. Majority of the healthcare professionals who have direct contact with clinical pharmacists in their work were generally receptive and have high expectations towards patient-oriented clinical pharmacy services.

Keywords: Clinical pharmacy, Perceptions, Expectations, Doctors, Nurses

"Corresponding author: limvching@hotmail.com

(C) Penerbit Universiti Sains Malaysia, 2020. This work is licensed under the terms of the Creative Commons Attribution (CC BY) (http://creativecommons.org/licenses/by/4.0/). 


\section{INTRODUCTION}

Traditionally, doctors diagnose diseases and prescribe drugs, while pharmacists compound and dispense drugs prescribed. However, this historic model has undergone tremendous changes over the years, as a result of increasingly complex drug therapies, significant technology advancements, booming information demands and changes in expectations of patients and other healthcare professionals on the roles of pharmacists (Lacaria et al. 2004). The roles of pharmacists have progressively expanded from a mere dispenser to pharmaceutical care provider, in which clinical pharmacy comes to play.

Clinical pharmacy is defined as the field of pharmacy practice whereby pharmacists provide patient care that optimises the drug therapy, while promoting health, wellness and disease prevention (American College of Clinical Pharmacy 2008). The clinical pharmacy discipline embraces the idea of pharmaceutical care, as introduced by Helper and Strand in 1990: the responsible provision of drug-related care in order to achieve definite clinical outcomes that improve patient's health-related quality of life, within realistic economic expenditures. The outcomes include cure of disease, eradication or reduction of patient's symptoms, halting or slowing of disease course, and preventing disease symptoms.

The introduction of clinical pharmacy discipline has led to the debut of clinical pharmacists in direct patient care environments, including wards, emergency departments, outpatient clinics, community pharmacies, nursing homes and managed care organisations (American College of Clinical Pharmacy 2014). Clinical pharmacists work directly with doctors, other healthcare professionals and patients to ensure the drugs prescribed are optimal, in terms of safety, appropriateness and effectiveness. Clinical pharmacists closely monitor patients' clinical progress, identify and alert doctors of any untreated medical problems that could be corrected or improved with appropriate drug therapy. Besides, clinical pharmacists also provide tailored advices on drugs usage and other nonpharmacological aspects of disease management, such as exercise, diet and preventive steps like immunisation, to best meet individual patient's therapeutic goals (American College of Clinical Pharmacy 2014).

In order to achieve the objective of clinical pharmacy services, clinical pharmacists ought to closely work in concert with patients and other healthcare professionals. All healthcare professionals should agree on each other's role, as different perceptions on the role of pharmacists could reduce the quality of teamwork (Mujires et al. 2003). In contrary, strong collaboration between the various healthcare professionals and their individual expertise will yield safer and more cost-effective pharmacotherapy (Zillich et al. 2006). Involvement of clinical pharmacists as pharmacotherapy experts in the multidisciplinary team of critical care units, have demonstrated profound improvement in patient outcomes through reductions in preventable adverse drug events, morbidity, mortality and drug cost (Society of Critical Care Drug and American College of Clinical Pharmacy 2000; Leape et al. 1999).

Nevertheless, some healthcare professionals may not necessarily be comfortable and well perceived with the increasing involvement of clinical pharmacists in direct patient care (Khdour et al. 2013; Matowe et al. 2006; Tahaineh et al. 2009). Nurses and especially doctors, are pivotal members of the multidisciplinary team in patient care. Investigating the notions of these healthcare professionals as well as identification of critical influencing factors that affect their perceptions and acceptance towards clinical pharmacy services are essential for successful implementation of the services.

The clinical pharmacy services of Tawau Hospital, Sabah, Malaysia have existed for almost a decade. Since then, the services have expanded with more clinical pharmacists being stationed in critical care wards. Clinical pharmacists are oriented towards medical,

Malay J Pharm Sci, Vol. 18, No. 1 (2020): 1-14 
critical care and surgical departments which tend to have a higher incidence of drug-related problems. Up to June 2014, there are seven full time clinical pharmacists in Male Medical Ward I \& II, Female Medical Ward I \& II, Intensive Care Unit/ Coronary Care Unit/ Pediatric Intensive Care Unit, Male Surgical Ward, Female Surgical Ward and Children Medical Ward in Tawau Hospital. To date, there are no published reports on the perceptions towards clinical pharmacy services originating from Tawau Hospital or anywhere else in Malaysia.

Accordingly, this study aims to evaluate the perceptions and expectations of healthcare professionals, particularly doctors and nurses, towards the role clinical pharmacists in Tawau Hospital. In addition, the comfort and experiences of these healthcare professionals while working with clinical pharmacists in direct patient care will also be examined. Findings from this study may provide a framework for further study to explore the potential barriers to greater involvement of clinical pharmacists in drugs management.

\section{METHODS}

\section{Study Design}

Cross sectional, questionnaire-based study design was used for this research. This research was carried out in the 10 wards (Male Medical Ward I \& II, Female Medical Ward I \& II, Intensive Care Unit/Coronary Care Unit/Pediatric Intensive Care Unit, Male Surgical Ward, Female Surgical Ward and Children Medical Ward) of Tawau Hospital with clinical pharmacy services from June to July 2014.

\section{Survey Development}

Prior to construction of the questionnaire, systematic search of published literatures was conducted to identify any existing validated surveys that could be used for the purpose of this study. The general principles of survey design as outlined by Zaidan et al. (2011) and Saira, Hassali and Ibrahim (2010) were adapted to the design of this 27-item questionnaire, with four sections: demographic, comfort level, expectations and experiences dealing with clinical pharmacists. Section 1 involved respondents' demographics, section 2 measured level of comfort with pharmacists carrying out specific duties, section 3 measured expectations towards the role clinical pharmacists, while section 4 measured the perceptions and actual experiences dealing with clinical pharmacists. Demographic information such as age, gender, current position, years of practice, frequency interaction with pharmacists and purpose of interaction was assessed in section 1 of the questionnaire. Sections 2, 3 and 4 comprised a set of statements in which the respondents were asked to indicate their level of agreement with, using a 4-point Likert scale, where 1 = strongly disagree, 2 = disagree; $3=$ agree; 4 = strongly agree. A 4-point Likert scale was adapted in order to eliminate possible misinterpretation of neutral responses. The content of the questionnaire, which was developed based on literature review and group discussion, was validated by experts who have at least three years of experience in pharmacy practice. The questionnaire was then being pre-tested for face validity among four healthcare professionals with a wide range of professional experience. Following pre-test, the questionnaire was revised and modified according to the views and comments obtained. The questionnaire was distributed with a covering letter explaining the purpose and benefits of the study, anonymity and confidentiality of the respondents, time frame of study distribution, questionnaire return instructions and consent for participation. 


\section{Participants}

The questionnaire was anonymously administered to two healthcare professional groups: (i) doctors, which include specialists, medical officers and house officers; (ii) nurses, which also include sisters. Self-administration of the questionnaire targeted at all accessible doctors and nurses (convenient sampling) who were affiliated to the wards with clinical pharmacists during the study period was used. Based upon previously conducted surveys, an $80 \%$ response rate was expected to be adequate for the purpose of characterising general opinions and perceptions of the various healthcare professional groups (Fahmy, Abdul Rasool and Abdu 2013; Abu-Gharbieh et al. 2010; Wilbur, Beniles and Hammuda 2012; Saira, Hassali and Ibrahim 2010). The minimum sample size required for this study was 500 for doctors and nurses in the wards that involved in clinical pharmacy services in Tawau Hospital. This figure was arrived with assumption of a $95 \%$ chance of our estimate being within $\pm 5 \%$ of the true population, $80 \%$ response rate and $50 \%$ of the respondents have positive perceptions towards clinical pharmacists based on literature review.

\section{Intervention and Data Collection}

The questionnaire was hand-delivered to the candidates by three investigators (pharmacists) who were not directly affiliated to the wards under study. These investigators were neither present nor involved in the completion of the questionnaire. In addition, they did not prompt nor attempt to influence the candidates' responses in any way. A one-week time frame was allocated for survey response. If the questionnaire has not been returned within a week, a reminder follow-up phone call was made to enhance response rate.

\section{Data Analysis}

All data collected was analysed using Statistical Package for the Social Sciences (SPSS) version 21. Descriptive statistical analysis was used to calculate the proportion of each group of respondents who agreed or disagreed with each statement in the questionnaire. Results for each question were reported as percentage, while any missing data was excluded from analysis.

\section{RESULTS}

\section{Sociodemographic Variables of Study Participants}

All accessible doctors and nurses who were affiliated to the wards with clinical pharmacists during the study period were enrolled in the study. Of the total 292 questionnaires administered, 269 were recovered, giving a total response rate of $92.1 \%$ as shown in Table 1 . The study participants comprised $76.6 \%$ females and $23.4 \%$ males, with a mean age of 27.8 years. Majority of the participants $(38.3 \%, n=103)$ were in the age range of $26-30$ years old. Of the total, $54.6 \%(n=147)$ were nurses, $17.8 \%(n=48)$ were house officers, $13.8 \%$ ( $n$ $=37)$ were medical officers, $7.4 \%(n=20)$ were specialists and consultants, while $6.3 \%(n=$ 17 ) were sisters. With regards to years of working experience, most of the participants $(44.6 \%$, $n=120)$ had less than two years of practice. More than half of the participants $(70.3 \%, n=$ 189) reported having frequent interactions with clinical pharmacists, in at least once a day. Participants' demographic information is shown in Table 2. Table 3 illustrates the reasons

Malay J Pharm Sci, Vol. 18, No. 1 (2020): 1-14 
of interactions between the participants and clinical pharmacists. The top five reasons for such interactions were to check on drug alternatives $(74 \%, n=199)$, availability of a drug in pharmacy $(69.1 \%, n=186)$, referral for counseling and Medication Therapy Adherence Clinic (MTAC) services $(63.2 \%, n=170)$, as well as queries on drug interaction $(40.1 \%$, $n=108)$ and drug administration $(39 \%, n=105)$. Meanwhile, only a small proportion of the participants interacted with clinical pharmacists to inquire drug dosages $(29.4 \%, n=79)$ and side effects $(27.5 \%, n=74)$.

Table 1: Response rate for each ward.

\begin{tabular}{lccc}
\hline Ward & $\begin{array}{c}\text { Number of questionnaire } \\
\text { administered }\end{array}$ & $\begin{array}{c}\text { Number of questionnaire } \\
\text { recovered }\end{array}$ & Percentage \\
\hline MMW1 & 21 & 18 & 85.7 \\
MMW2 & 20 & 17 & 85.0 \\
FMW1 & 17 & 15 & 88.2 \\
FMW2 & 16 & 15 & 93.8 \\
ICU & 71 & 68 & 95.8 \\
CCU & 32 & 30 & 93.8 \\
PICU & 20 & 18 & 90.0 \\
MSW & 32 & 29 & 90.6 \\
FSW & 29 & 28 & 96.6 \\
CMW & 34 & 31 & 91.2 \\
\hline Total & 292 & 269 & 92.1 \\
\hline
\end{tabular}

Table 2: Demographic characteristics of the study participants $(N=269)$.

\begin{tabular}{lcc}
\hline Variable & Number & Percentage \\
\hline Gender & 63 & \\
$\quad$ Male & 206 & 23.4 \\
Female & & 76.6 \\
Age & 97 & \\
25 years old \& below & 103 & 36.1 \\
26-30 years old & 28 & 38.3 \\
31-35 years old & 22 & 10.4 \\
36-40 years old & 19 & 8.2 \\
41 years old \& above & & 7.1 \\
Profession & 20 & \\
Specialist/Consultant & 37 & 7.4 \\
Medical officer & 48 & 13.8 \\
House officer & 17 & 17.8 \\
Sister & 147 & 6.3 \\
Nurse & & 54.6 \\
\hline
\end{tabular}

(continued on next page) 
Table 2: (continued)

\begin{tabular}{lcc}
\hline Variable & Number & Percentage \\
\hline Years of working experience & & \\
$\quad$ Less than 2 years & 120 & 44.6 \\
2-<4 years & 53 & 19.7 \\
4-<6 years & 36 & 13.4 \\
6-<8 years & 5 & 1.9 \\
8-<10 years & 15 & 5.6 \\
10 years \& above & 40 & 14.9 \\
Frequency of interaction & & \\
Never/rarely & 23 & 8.6 \\
Once a week & 57 & 21.2 \\
Once a day/more & 189 & 70.3 \\
\hline
\end{tabular}

Table 3: Reasons of interaction with clinical pharmacists.

\begin{tabular}{lcc}
\hline Reason for interaction & Number & Percentage \\
\hline Drug availablity query & 186 & 69.1 \\
Drug alternative query & 199 & 74.0 \\
Drug dosage query & 79 & 29.4 \\
Side effect query & 74 & 27.5 \\
Drug interaction query & 108 & 40.1 \\
Drug administration query & 105 & 39.0 \\
Counseling/MTAC service referral & 170 & 63.2 \\
\hline
\end{tabular}

\section{Comfort of Doctors and Nurses on the Role of Clinical Pharmacists in Direct Patient Care}

Results showing the level of comfort of doctors and nurses towards the roles of clinical pharmacists in direct patient care are listed in Table 4. In general, majority of the study participants were comfortable with clinical pharmacists providing drug-related patient education (92.2\%), suggesting the usage of drugs to prescribers (92.6\%), designing and monitoring safety of drug therapy regimens (93.7\%), monitoring outcomes of drug therapy regimens (93.3\%), as well as detecting and preventing prescription errors $(95.6 \%)$. Compared to the nurses group, higher percentage of doctors were less comfortable with clinical pharmacists providing drug-related education to patients, suggesting the use of drugs to prescribers, designing pharmacotherapy regimes, and monitoring safety and outcomes of the designed regimens. 
Table 4: Level of comfort of doctors and nurses on the role of clinical pharmacists in direct patient care.

\begin{tabular}{llcccc}
\hline \multirow{2}{*}{$\begin{array}{l}\text { Role of } \\
\text { pharmacist }\end{array}$} & $\begin{array}{l}\text { Healthcare } \\
\text { professional }\end{array}$ & $\begin{array}{l}\text { Strongly } \\
\text { disagree }\end{array}$ & Disagree & Agree & $\begin{array}{c}\text { Strongly } \\
\text { agree }\end{array}$ \\
\hline A & Doctor & $5(4.8)$ & $10(9.5)$ & $50(47.6)$ & $40(38.1)$ \\
& Nurse & 0 & $6(3.7)$ & $115(70.1)$ & $43(26.2)$ \\
& Total & $5(1.9)$ & $16(6)$ & $165(61.3)$ & $83(30.9)$ \\
B & Doctor & $2(1.9)$ & $12(11.4)$ & $54(51.4)$ & $37(35.2)$ \\
& Nurse & 0 & $6(3.7)$ & $112(68.3)$ & $46(28.1)$ \\
& Total & $2(0.7)$ & $18(6.7)$ & $166(61.7)$ & $83(30.9)$ \\
C & Doctor & $3(2.9)$ & $8(7.6)$ & $52(49.5)$ & $42(40)$ \\
& Nurse & 0 & $6(3.7)$ & $112(68.3)$ & $46(28.1)$ \\
& Total & $3(1.1)$ & $14(5.2)$ & $164(61)$ & $88(32.7)$ \\
D & Doctor & $2(1.9)$ & $7(6.7)$ & $56(53.3)$ & $40(38.1)$ \\
& Nurse & 0 & $9(5.5)$ & $104(63.4)$ & $51(31.1)$ \\
& Total & $2(0.7)$ & $16(6)$ & $160(59.5)$ & $91(33.8)$ \\
& Doctor & $3(2.9)$ & $4(3.8)$ & $49(46.7)$ & $49(46.7)$ \\
& Nurse & 0 & $5(3.1)$ & $104(63.4)$ & $55(33.5)$ \\
& Total & $3(1.1)$ & $9(3.4)$ & $153(56.9)$ & $104(38.7)$ \\
\hline
\end{tabular}

Notes:

$A=$ Provide drug-related patient education

$B=$ Suggest the use of drugs to prescribers

$\mathrm{C}=$ Design and monitor safety of drug therapy regimens

$\mathrm{D}=$ Monitor outcomes of drug therapy regimens

$\mathrm{E}=$ Detect and prevent prescription errors

${ }^{*}$ Responses were made on a 4-point Likert scale

\section{Expectations of Doctors and Nurses on the Role of Clinical Pharmacists in Direct Patient Care}

Expectations of the participants towards the roles of clinical pharmacists are tabulated in Table 5 below. Overall, most of the participants agreed to the expectations outlined in the questionnaire with $97 \%$ of the participants expected clinical pharmacists to educate patients on the safe and appropriate drug use. Clinical pharmacists are expected to be available for consultation during ward rounds and know the specific indications of each drug prescribed, as agreed by $95.9 \%$ and $95.5 \%$ of participants, respectively. Clinical pharmacists, who were regarded to be knowledgeable in pharmacotherapy by $95.2 \%$ of the participants, are expected to monitor patient's response to drug therapy (93.3\%) and assist in designing drug therapy plans (92.9\%). However, only $89.6 \%$ of the participants expected clinical pharmacists to take personal responsibility for resolving any medicine-related problems discovered. 
Table 5: Expectations of doctors and nurses on the role of clinical pharmacists in direct patient care.

\begin{tabular}{|c|c|c|c|c|c|}
\hline \multirow{2}{*}{$\begin{array}{l}\text { Role of } \\
\text { pharmacist }\end{array}$} & \multirow{2}{*}{$\begin{array}{l}\text { Healthcare } \\
\text { professional }\end{array}$} & \multicolumn{4}{|c|}{ Response*, $n(\%)$} \\
\hline & & $\begin{array}{l}\text { Strongly } \\
\text { disagree }\end{array}$ & Disagree & Agree & $\begin{array}{l}\text { Strongly } \\
\text { agree }\end{array}$ \\
\hline \multirow[t]{3}{*}{ A } & Doctors & $3(2.9)$ & $19(18.1)$ & $55(52.4)$ & $28(26.7)$ \\
\hline & Nurses & $1(0.6)$ & $5(3.1)$ & $72(43.9)$ & $86(52.4)$ \\
\hline & Total & $4(1.5)$ & $24(8.9)$ & $127(47.2)$ & $114(42.4)$ \\
\hline \multirow[t]{3}{*}{ B } & Doctors & $2(1.9)$ & $6(5.7)$ & $43(41)$ & $54(51.4)$ \\
\hline & Nurses & $1(0.6)$ & $4(2.4)$ & $60(36.6)$ & $99(60.4)$ \\
\hline & Total & $3(1.1)$ & $10(3.7)$ & $103(38.3)$ & $153(56.9)$ \\
\hline \multirow[t]{3}{*}{ C } & Doctors & $1(1)$ & $13(12.4)$ & $59(56.2)$ & $32(30.5)$ \\
\hline & Nurses & 0 & $5(3.1)$ & $80(48.8)$ & $79(48.2)$ \\
\hline & Total & $1(0.4)$ & $18(6.7)$ & $139(51.7)$ & $111(41.3)$ \\
\hline \multirow[t]{3}{*}{ D } & Doctors & $2(1.9)$ & $3(2.9)$ & $44(41.9)$ & $56(53.3)$ \\
\hline & Nurses & 0 & $3(1.8)$ & $65(39.6)$ & $96(58.6)$ \\
\hline & Total & $2(0.7)$ & $6(2.2)$ & $109(40.5)$ & $152(56.5)$ \\
\hline \multirow[t]{3}{*}{$\mathrm{E}$} & Doctors & $2(1.9)$ & $14(13.3)$ & $58(55.3)$ & $31(29.5)$ \\
\hline & Nurses & 0 & $2(1.2)$ & $76(46.3)$ & $86(52.4)$ \\
\hline & Total & $2(0.7)$ & $16(6)$ & $134(49.8)$ & $117(43.5)$ \\
\hline \multirow[t]{3}{*}{$\mathrm{F}$} & Doctors & $2(1.9)$ & $8(7.6)$ & $47(44.8)$ & $48(45.7)$ \\
\hline & Nurses & 0 & $2(1.2)$ & $64(39)$ & $98(59.8)$ \\
\hline & Total & $2(0.7)$ & $10(3.7)$ & $111(41.3)$ & $146(54.3)$ \\
\hline \multirow[t]{3}{*}{ G } & Doctors & $1(1)$ & $8(7.6)$ & $37(35.2)$ & $59(56.2)$ \\
\hline & Nurses & 0 & $2(1.2)$ & $53(32.3)$ & $109(66.5)$ \\
\hline & Total & $1(0.4)$ & $10(3.7)$ & $90(33.5)$ & $168(62.5)$ \\
\hline
\end{tabular}

Notes:

$\mathrm{A}=$ Take personal responsibility for resolving any medicine-related problems discovered

$\mathrm{B}=$ Knowledgeable in drug therapy

$\mathrm{C}=$ Assist in designing drug therapy plans

$\mathrm{D}=$ Educate patients about safe and appropriate use of drugs

$\mathrm{E}=$ Monitor patients' response to drug therapy

$\mathrm{F}=$ Know the specific indication of each drug prescribed

$\mathrm{G}=$ Available for consultation during ward rounds

${ }^{*}$ Responses were made on a 4-point Likert scale 


\section{Perceptions and Actual Experiences of Doctors and Nurses with Clinical Pharmacists of Tawau Hospital}

Table 6 shows the perceptions and actual experiences with clinical pharmacists of Tawau Hospital, in terms of clinical knowledge and professionalism. In overall, the participants have good perceptions and experiences with clinical pharmacists of Tawau Hospital. Majority $(95.6 \%)$ regarded clinical pharmacists as reliable source of drug information, while $93.7 \%$ believed that clinical pharmacists can minimise medication errors, maximise cost effectiveness and improve therapeutic outcomes. There is a strong view that clinical pharmacists effectively counsel patients on safe and appropriate drug use (94.4\%), as well as frequently inform any prescription-related problems detected (96.9\%) and drugrelated issues experienced by patients $(92.2 \%)$. However, the participants' believe in clinical pharmacists' capacity to provide a solution for any drug-related issues discovered and willingness to take personal responsibility for any drug-related problems discovered are relatively lower, with only $90.7 \%$ and $90.3 \%$ were agreeing. Although majority of the participants (94\%) agreed that clinical pharmacists' representation in clinical ward rounds is desirable, only $88.5 \%$ perceived that clinical pharmacists have fulfilled their expected roles in Tawau Hospital.

Table 6: Perceptions and actual experiences of doctors and nurses with clinical pharmacists of Tawau Hospital.

\begin{tabular}{llcccc}
\hline \multirow{2}{*}{ Statement } & $\begin{array}{l}\text { Healthcare } \\
\text { professional }\end{array}$ & $\begin{array}{l}\text { Strongly } \\
\text { disagree }\end{array}$ & Disagree & Agree & $\begin{array}{c}\text { Strongly } \\
\text { agree }\end{array}$ \\
\cline { 2 - 6 } A & $2(1.9)$ & $6(5.7)$ & $53(50.5)$ & $44(41.9)$ \\
& Doctors & 0 & $4(2.4)$ & $93(56.7)$ & $67(40.9)$ \\
& Nurses & $2(0.7)$ & $10(3.7)$ & $146(54.3)$ & $111(41.3)$ \\
B & Total & $3(2.9)$ & $16(15.2)$ & $47(44.8)$ & $39(37.1)$ \\
& Doctors & $1(0.6)$ & $6(3.7)$ & $94(57.3)$ & $63(38.4)$ \\
& Nurses & $4(1.5)$ & $22(8.2)$ & $141(52.4)$ & $102(37.9)$ \\
C & Total & 0 & $11(10.5)$ & $55(52.4)$ & $39(37.1)$ \\
& Doctors & 0 & $4(2.4)$ & $96(58.6)$ & $64(39)$ \\
& Nurses & 0 & $15(5.6)$ & $151(56.1)$ & $103(38.3)$ \\
D & Total & $7(4.8)$ & $7(6.7)$ & $52(49.5)$ & $41(39.1)$ \\
& Doctors & 0 & $5(3.1)$ & $93(56.7)$ & $66(40.2)$ \\
& Nurses & $12(4.5)$ & $145(53.9)$ & $107(39.8)$ \\
& Total & $5(1.9)$ & $12(11.4)$ & $48(45.7)$ & $42(40)$ \\
& Doctors & $3(2.9)$ & $6(3.7)$ & $102(62.2)$ & $56(34.2)$ \\
& Nurses & 0 & $18(6.7)$ & $150(55.8)$ & $98(36.4)$ \\
\hline
\end{tabular}

(continued on next page) 
Table 6: (continued)

\begin{tabular}{llcccc}
\hline \multirow{2}{*}{ Statement } & $\begin{array}{l}\text { Healthcare } \\
\text { professional }\end{array}$ & $\begin{array}{l}\text { Strongly } \\
\text { disagree }\end{array}$ & Disagree & Agree & $\begin{array}{c}\text { Strongly } \\
\text { agree }\end{array}$ \\
\cline { 3 - 6 } & Doctors & $3(2.9)$ & $15(14.3)$ & $44(41.9)$ & $43(41)$ \\
& Nurses & 0 & $7(4.3)$ & $97(59.2)$ & $60(36.6)$ \\
T & $3(1.1)$ & $22(8.2)$ & $141(52.4)$ & $103(38.3)$ \\
& Total & $3(2.9)$ & $11(10.5)$ & $41(39.1)$ & $50(47.6)$ \\
& Doctors & 0 & $3(1.8)$ & $106(64.6)$ & $55(33.6)$ \\
& Nurses & $3(1.1)$ & $14(5.2)$ & $147(54.7)$ & $105(39)$ \\
$\mathrm{H}$ & Total & $1(1)$ & $14(13.3)$ & $38(36.2)$ & $52(49.5)$ \\
& Doctors & 0 & $1(0.6)$ & $74(45.1)$ & $89(54.3)$ \\
& Nurses & $1(0.4)$ & $15(5.6)$ & $112(41.6)$ & $141(52.4)$ \\
& Total & 0 & $20(19.1)$ & $50(47.6)$ & $35(33.3)$ \\
& Doctors & $2(1.2)$ & $9(5.5)$ & $103(62.8)$ & $50(30.5)$ \\
& Nurses & $2(0.7)$ & $29(10.8)$ & $153(56.9)$ & $85(31.6)$ \\
\hline
\end{tabular}

Notes:

$A=$ Clinical pharmacists are reliable source of drug information

$\mathrm{B}=$ Clinical pharmacists appear willing to take personal responsibility for any drug-related problems discovered

$\mathrm{C}=$ Clinical pharmacists effectively counsel patients regarding the safe and appropriate use of their drugs

$\mathrm{D}=$ Clinical pharmacists always inform any clinical problems discovered with drug prescriptions

$\mathrm{E}=$ Clinical pharmacists always inform any drug-related issues experienced by patients

$\mathrm{F}=$ Clinical pharmacists always provide a solution for any drug-related issues discovered

$\mathrm{G}=$ Clinical pharmacist can minimise medication errors, maximise cost effectiveness and improve therapeutic outcomes

$\mathrm{H}=$ Clinical pharmacy representation in clinical ward rounds is desirable

I = Clinical pharmacist have fulfilled their expected roles in Tawau Hospital

${ }^{*}$ Responses were made on a 4-point Likert scale

\section{DISCUSSION}

The advancement of pharmacy practice in different areas of Malaysia varies significantly from one another. In the case of Tawau, the pharmacy profession, particularly in terms of pharmaceutical care, is considerably at an early stage of development. The shortage of pharmacists in Tawau Hospital has resulted in selective participation of pharmacists in the clinical ward setting. Consequently, the roles of pharmacists in this hospital are rather limited to drug dispensing, counseling, procurement and inventory control, as perceived by some participants in this study.

When asked about the frequency of interactions with clinical pharmacists, only $70.3 \%$ of the participants claimed having at least one interaction in a day, whilst $8.6 \%$ never do. The main reasons for such interactions were to check on drug alternatives (74\%), drug availability $(69.1 \%)$ and referral for medication counseling $(63.2 \%)$, thus showing that the pharmacist is regarded as procurer and dispenser of medicines, rather than pharmaceutical care provider. Similar finding has also been reported in the study by Saira, Hassali and Ibrahim (2010). 
Successful implementation of clinical pharmacy practice requires good cooperation between doctors, nurses and pharmacists. All healthcare professionals should agree on each other's role, as different perceptions could reduce the quality of teamwork (Mujires et al. 2003). Nurses and particularly doctors, are pivotal members of the multidisciplinary team in patient care. Thus, high level of comfort and acceptance by these healthcare professionals towards clinical pharmacists are vital for effective operation of ward based clinical pharmacy services.

Previous studies have shown some variation in the trend of healthcare professionals' acceptance, perceptions and expectations towards the role of clinical pharmacists in direct patient care. While many previous studies demonstrated that majority of healthcare professionals were generally receptive and have high expectations towards patient-oriented clinical pharmacy services, some doctors may not necessarily be comfortable and well perceived with the increasing involvement of clinical pharmacists in direct patient care as lack of exposure to participation of pharmacists which was demonstrated in the previous studies conducted in Palestine, Kuwait and Jordan (Khdour et al. 2013; Matowe et al. 2006; Tahaineh et al. 2009).

This study described the perceptions, expectations and comfort of doctors and nurses towards the role clinical pharmacists in Tawau Hospital. Like many previous studies, this study revealed that majority of the healthcare professionals who have direct contact with clinical pharmacists in their work were generally receptive and have high expectations towards patient-oriented clinical pharmacy services (Abu-Gharbieh et al. 2010; Berhane et al. 2013; Fahmy, Abdul Rasool and Abdu 2013; Haxby, Weart and Goodman 1988; Saira, Hassali and Ibrahim 2010; Saira et al. 2012).

However, there are notable disparities in the trend of two participant groups' comfort, perceptions and expectations towards the role of clinical pharmacists in direct patient care. Compared to the nurses' group, significantly more doctors showed low comfort, perceptions and expectations of patient-oriented clinical pharmacist roles. Doctors were found to be comparatively more comfortable with product-oriented roles of pharmacists, like detecting prescription errors, than patient-oriented consultative roles, such as suggesting drug use to prescribers and assisting in drug regimen design. Similar trend on comfort level of physicians has also been reported in Qatar by Wilbur, Beniles and Hammuda (2012).

In this study, nurses showed consistent strong expectations towards all the roles of clinical pharmacists. However, comparable trend was not found in doctors. Doctors had highest expectations of pharmacists educating patients on safe and appropriate drug use, besides being knowledgeable in drug therapy. These findings were consistent with previous studies reported in Qatar, Palestine, Jordan, Sudan and Kuwait (Awad, Matowe and Capps 2007; Khdour et al. 2013; Matowe et al. 2006; Tahaineh et al. 2009; Wilbur, Beniles and Hammuda 2012; Zaidan et al. 2011). While $95.2 \%$ of the doctors in this study expected pharmacists to educate patients on drug use, a non-corresponding $14.3 \%$ was surprisingly reported uncomfortable with pharmacists' role of providing drug-related patient education.

Comparatively lower expectations of doctors were found on pharmacists taking personal responsibility for resolving drug-related issues, assisting doctors in pharmacotherapy design and monitoring patients' response to drug therapy. Alike findings have also been detected in some previous studies (Awad, Matowe and Capps 2007; Berhane et al. 2013; Khdour et al. 2013; Matowe et al. 2006; Saira, Hassali and Ibrahim 2010; Tahaineh et al. 2009; Wilbur, Beniles and Hammuda 2012; Zaidan 2011). Conversely, the study in Pakistan by Saira, Hassali and Ibrahim (2010) revealed highest doctors' expectations of pharmacists was on monitoring patients' pharmacotherapeutic response, whilst expectation of pharmacists as educators on safe and appropriate use of drugs appeared least. 
In regards to years of practice, the pattern of expectations towards role of clinical pharmacists showed dissimilarity, consistent with the results of the studies reported in Qatar, Palestine, Jordan, Sudan and Kuwait (Awad, Matowe and Capps 2007; Khdour et al. 2013; Matowe et al. 2006; Tahaineh et al. 2009; Wilbur, Beniles and Hammuda 2012; Zaidan et al. 2011).

With regards to perceptions towards clinical pharmacists of Tawau Hospital, majority of the participants reported having good experiences and positive perceptions. Nonetheless, doctors' responses towards all items assessing perceptions were dissimilar in trend if compared to that of nurses' group. Nurses showed strong agreement to all items assessing perception, while doctors' responses were comparatively more neutral.

Alike in many previous studies, majority of the doctors in this study perceived that pharmacists effectively counsel patients regarding the safe and appropriate use of their drugs, on top of being a reliable source of drug information (Matowe et al. 2006; Saira, Hassali and Ibrahim 2010; Wilbur, Beniles and Hammuda 2012; Zaidan et al. 2011). Perceptions and experiences on the other roles of clinical pharmacists as reported in this study differ modestly from earlier studies. Although majority of the doctors in this study agreed that clinical pharmacists are willing to take personal responsibility for any drugrelated problems discovered and will inform any drug-related issues experienced by patients besides providing a solution for any drug-related issues, the number agreeing to these statements are comparatively lesser than the statements mentioned earlier. In contrary, these perceptions were disagreed by majority doctors in previous studies in Kuwait, Pakistan and Qatar (Matowe et al. 2006; Saira, Hassali and Ibrahim 2010; Zaidan et al. 2011).

When participants were asked if clinical pharmacists have fulfilled their roles in Tawau Hospital, and if clinical pharmacy representation in clinical ward rounds is desirable, their responses were mainly positive. In addition, majority of the participants in this study, including doctors, have high level of expectations on availability of clinical pharmacists for consultation during ward rounds, as contrary to previous studies (Awad, Matowe and Capps 2007; Berhane et al. 2013; Khdour et al. 2013; Matowe et al. 2006; Saira, Hassali and Ibrahim 2010; Tahaineh et al. 2009; Wilbur, Beniles and Hammuda 2012; Zaidan 2011). This signifies that clinical pharmacy services have a higher level of acceptance and perception in Tawau Hospital. However, there was lesser agreement among the doctors. Similar findings have also been found in previous studies where a much smaller number of doctors agreed when asked if there was an increasing interest in clinical pharmacy services in the institutions and if clinical pharmacists have fulfilled their roles in the studied institutions (Abu-Gharbieh et al. 2010; Fahmy, Abdul Rasool and Abdu 2013).

There are several limitations in this study. Despite the fact that the questionnaire underwent content validity test, the study questionnaire was not examined for construct validity or reliability. In addition, the targeted population in Tawau Hospital is insufficient to cater the estimated sample size. Accordingly, caution must be exercised when attempting to extrapolate the results to the institution as a whole or to other institutions in general.

\section{CONCLUSION}

Significantly more doctors showed low comfort, perceptions and expectations of patientoriented clinical pharmacist roles compared to nurses. In summary, findings from this study revealed that healthcare professionals in Tawau Hospital acknowledged the role of clinical pharmacists in direct patient care and they are willing to collaborate with clinical pharmacists to improve therapeutic outcome. Thus, new measures to extend clinical pharmacy services

Malay J Pharm Sci, Vol. 18, No. 1 (2020): 1-14 
to all the wards in Tawau Hospital should be adopted. Results of this study also serve as a platform for further study to explore the potential barriers to greater involvement of clinical pharmacists in drug management.

\section{REFERENCES}

ABU-GHARBIEH E., FAHMY S. A., ABDUL RASOOL B. K., ABDUELKAREM A. \& BASHETI I. (2010) Attitudes and perceptions of healthcare providers and medical students towards clinical pharmacy services in United Arab Emirates, Tropical Journal of Pharmaceutical Research, 9(5): 421-430. https://doi.org/10.4314/tjpr.v9i5.61050

AMERICAN COLLEGE OF CLINICAL PHARMACY. (2008) The definition of clinical pharmacy, Pharmacotherapy, 28(6): 816-817. https://doi.org/10.1592/phco.28.6.816

AMERICAN COLLEGE OF CLINICAL PHARMACY. (2014) About clinical pharmacists. http://www.accp.com/about/clinicalpharmacists.aspx (23 April 2014).

AWAD A., MATOWE L. \& CAPPS P. (2007) Medical doctors' perceptions and expectations of the role of hospital pharmacists in Sudan, Pharmacy World \& Science, 29: 557-564. https://doi.org/10.1007/s11096-007-9111-5

BERHANE A., ALI E., ODEGARD P. \& SULEMAN S. (2013) Physicians' expectations of clinical pharmacists' roles in Jimma University Specialized Hospital, South-west Ethiopia, International Journal of Pharmacy Teaching \& Practices, 4: 571-574.

FAHMY S. A., ABDUL RASOOL B. K. \& ABDU S. (2013) Health-care professional's perceptions and expectations of pharmacists' roles in the emergency department, United Arab Emirates, Eastern Mediterranean Health Journal, 19(9): 794-801. https://doi.org/10.26719/2013.19.9.794

HAXBY D. G., WEART C. W. \& GOODMAN B. W. Jr. (1988) Family practice physicians' perceptions of the usefulness of drug therapy recommendations from clinical pharmacists, American Journal of Hospital Pharmacy, 45(4): 824-827. https://doi.org/10.1093/ ajhp/45.4.824

HEPLER C. D. \& STRAND L. M. (1990) Opportunities and responsibilities in pharmaceutical care, American Journal of Hospital Pharmacy, 47(3): 533-543. https://doi.org/10.1093/ ajhp/47.3.533

KHDOUR M. R., ALAYASA K. S., ALSHAHED Q. N. \& HAWAA A. F. (2013) Physicians' perceptions, attitudes and expectations regarding the role of hospital-based pharmacists in the West Bank, Palestine, International Journal of Pharmacy Practice, 21(3): 178-184. https://doi.org/10.1111/j.2042-7174.2012.00246.x

LACARIA K., BALEN R. M., FRIGHETTO L., LAU T. T. Y., NAUMANN T. L. \& JEWESSON P. J. (2004) Perceptions of the professional pharmacy services in a major Canadian hospital: A comparison of stakeholder groups, Longwoods Rev, 2: 8-19. 
LEAPE L. L., CULLEN D. J., CLAPP M. D., BURDICK E., DEMONACO H. J., ERICKSON J. I. et al. (1999) Pharmacist participation on physician rounds and adverse drug events in the intensive care unit, JAMA, 282(3): 267-270. https://doi.org/10.1001/jama.282.3.267

MATOWE L., ABAHUSSAIN E. A., AL-SAFFAR N., BIHZAD S. M., AL-FORAIH A. \& AL-KANDERY A. A. (2006) Physician's perceptions and expectations of pharmacists' professional duties in government hospitals in Kuwait, Medical Principles and Practice, 15(3): 185-189. https://doi.org/10.1159/000092179

MUJIRES P. E., KNOTTNERUS J. A., SAIJBRANDIJ J., JANKNEGT R. \& GROL R. P. (2003) Changing relationship: Attitude and opinion of general practitioners and pharmacist regarding the role of the community pharmacist, Pharmacy World and Science, 25: 235241. https://doi.org/10.1023/A:1025872907411

SAIRA A., HASSALI M. A. \& IBRAHIM M. I. M. (2010) Doctors' perception and expectations of the role of the pharmacist in Punjab, Pakistan, Tropical Journal of Pharmaceutical Research, 9(3): 205-222. https://doi.org/10.4314/tjpr.v9i3.56279

SAIRA A., HASSALI M. A., IBRAHIM M. I. M., SALEEM F. \& LIAU S. Y. (2012) A survey evaluating nurses' perception and expectations towards the role of pharmacist in Pakistan's healthcare system, J Adv Nurs, 68(1): 199-205. https://doi.org/10.1111/ j.1365-2648.2011.05728.x

SOCIETY OF CRITICAL CARE DRUG AND AMERICAN COLLEGE OF CLINICAL PHARMACY. (2000) Position paper on critical care pharmacy services, Pharmacotherapy, 20(11): 1400-1406. https://doi.org/10.1592/phco.20.17.1400.34893

TAHAINEH L. M., WAZAIFY M., ALBSOUL-YOUNES A., KHADER Y. \& ZAIDAN M. (2009) Perceptions, experiences and expectations of physicians in hospital settings in Jordan regarding the role of the pharmacist, Research in Social and Administrative Pharmacy, 5(1): 63-70. https://doi.org/10.1016/j.sapharm.2008.05.003

WILBUR K., BENILES A. \& HAMMUDA A. (2012) Physician perceptions of pharmacist roles in a primary care setting in Qatar, Globalization and Health, 8: 12. https://doi.org/ 10.1186/1744-8603-8-12

ZAIDAN M., SINGH R., WAZAIFY M. \& TAHAINEH L. (2011) Physicians' perceptions, expectations and experience with pharmacists at Hamad Medical Corporation in Qatar, Journal of Multidisciplinary Healthcare, 4: 85-90. https://doi.org/10.2147/JMDH.S14326

ZILLICH A. J., MILCHAK J. L., CARTER B. L. \& DOUCETTE W. R. (2006) Utility of a questionnaire to measure physician pharmacist collaborative relationship, Journal of American Pharmacists Association, 46(4): 453-458. https://doi.org/10.1331/ 154434506778073592 